\title{
Is it common to be rare on the landscape? A test using a novel model system
}

\author{
Yolanda F. Wiersma $\mathbb{D} \cdot$ R. T. McMullin
}

Received: 7 September 2017/Accepted: 7 December 2017/Published online: 13 December 2017

(C) The Author(s) 2017. This article is an open access publication

\begin{abstract}
Context Understanding how rare species are distributed can be difficult due to heterogeneity between landscape units. Lack of statistical replication of landscapes can make it difficult to carry out testing. Model systems may be a solution.

Objectives We test whether lichen thalli along the trunk of a tree are analogous to habitat patches in a kilometers-extent landscape and hence can function as a model system. This model system allows for increased statistical power. We use this system to test whether landscapes with rare species are different from those without.

Methods We sampled macrolichen diversity along the trunk of 24 balsam fir trees in a stand on the Avalon Peninsula, Newfoundland, Canada, along with microclimate variables. We analysed difference in pattern by aspect and along the gradient of $1 \mathrm{~m}$ up the trunk as
\end{abstract}

Electronic supplementary material The online version of this article (https://doi.org/10.1007/s10980-017-0599-3) contains supplementary material, which is available to authorized users.

Y. F. Wiersma $(\bowtie)$

Department of Biology, Memorial University of

Newfoundland, St. John's, NL A1B 3X9, Canada

e-mail: ywiersma@mun.ca

R. T. McMullin

Canadian Museum of Nature, Research and Collections,

Station D, PO Box 3443, Ottawa, ON K1P 6P4, Canada well as between trees containing the rare Erioderma pedicellatum and those without.

Results We found no difference in total patch richness or abundance between the micro-landscapes. We found significantly consistent patterns in lichen patches along the trunk. These patterns were similar on the trees with the rare species. Lichen species richness did not differ between trees containing the rare species versus those that did not.

Conclusions Lichen patch pattern is statistically similar between trees and as such, these can be considered as replicate landscape units. Thus, landscape ecologists can use micro-landscapes as model systems to conduct observational and manipulative experiments to test questions about spatial pattern and process, such as those concerning distribution of rare species.

Keywords Biodiversity - Boreal forest - Lichens . Micro-landscape $\cdot$ Patch pattern · Rank-abundance Rarity $\cdot$ Species distribution

\section{Introduction}

Understanding the distribution of rare species can yield important insights for both ecology and conservation. Notwithstanding species whose rarity is due to population declines as a result of anthropogenic 
pressures, there are as many (if not more) species that are naturally rare than are common (Gaston 1994; Kunin and Gaston 1997). Rabinowitz (1981) developed classifications for rarity based on geographic range, local abundance and habitat specificity. Similarly, Kunin and Gaston (1997) defined different forms of rarity, including species that are sparsely dispersed across a wide spatial extent or those that occur in high density but only within a limited spatial extent. Gaston (1994) emphasized that rarity (or commonness) must always be described in reference to a particular spatial scale, and that there may not always be spatial concordance in rarity (that is, species that are rare in one area are also rare somewhere else). Gaston (1994, p. 78) defined four criteria to test for spatial concordance in rarity; (1) individual species must fall consistently within the rare category, (2) species composition of the rare category should be the same, (3) the rank abundances or range sizes of the rare species should be the same, and (4) the rank abundances or range sizes of all the species should be the same. However, it can be difficult to find studies that document spatial concordance of rarity (Gaston 1994; McGeoch and Chown 1997), partly due to the difficulty of measuring abundance or range size of other species beyond the rare one of interest. Gaston (1994, p. 81) posits that high concordance in rarity is more probable when the habitats being compared are similar to each other, and in closer proximity to each other. This has been echoed by more recent studies. For example, Alahuhta et al. (2014) looked at community composition of rare and common macrophytes in a metacommunity context and concluded that it was difficult to derive general conclusions about the response of rare and common species to ecological gradients because of spatial variation across scales. Similarly, Murray et al. (2002) looked at life-history and ecological traits in plants across spatial scales and found that some species could be considered rare at small or broad spatial extents but were common at intermediate extents.

If rarity is in the form of being patchily distributed across a wide geographic extent, then spatial differences in the environments from which individuals are sampled can confound the analysis. A rare species that occurs across a wide (10-1000 s of kilometers) geographic range may be found in multiple landscapes that are not directly comparable. Thus, it can be difficult to generalize what drives the species distribution. An example of such a species with a patchy distribution across a pan-boreal extent is the boreal felt lichen (Erioderma pedicellatum (Hue) P.M. Jorg.), which is red-listed by the International Union for the Conservation of Nature (IUCN; Scheidegger 2003). It has been challenging to elucidate the factors determining its occurrence at the spatial extent of the $108,860 \mathrm{~km}^{2}$ island of Newfoundland (where over $95 \%$ of the global distribution occurs) (Wiersma and Skinner 2011), likely in part due to variation in environments at these macro-scale extents. In Atlantic Canada, it is known to prefer humid, older balsam fir (Abies balsamea) stands near the coast (Cameron and Neily 2008; Wiersma and Skinner 2011) and be sensitive to air pollution (Cameron et al. 2013) and disturbance from logging (Maass and Yetman 2002; Cameron et al. 2013). However, many stands that appear suitable do not contain E. pedicellatum. At the scale of trees within a homogenous stand (hectares), the occurrence of the lichen has also been difficult to explain when comparing stands in Alaska, Kamchatka and Newfoundland, where it occurs primarily on black spruce (Picea glauca). This is due perhaps in part to geographic limitation of the photobiont's haplotype diversity in Newfoundland and an apparent complex tripartite association between E. pedicellatum, its photobiont (which it shares with Coccocarpia palmicola; Cornejo et al. 2016), and the liverwort Frullania asagrayana (Cornejo and Scheidegger 2016). It is also possible that subtle variation between individual trees or the microclimate at that tree is driving presence/ absence of E. pedicellatum.

Robust hypotheses testing about factors driving the distribution of a rare species, along with tests for spatial concordance in rarity, requires experimental replicates. The field of landscape ecology has long grappled with the challenge of replication when working at landscapes which are kilometres in extent. This lack of replication makes it difficult to rigorously conduct manipulative experiments (Wiens and Milne 1989; Ims 2005) and to have sufficient replication of experimental units to enable robust statistical hypothesis testing (Wiens and Milne 1989; Hargrove and Pickering 1992).Strategies to conduct experiments in landscape ecology have been proposed (Jenerette and Shen 2012) but often have trade-offs with respect to scaling, generalizability or relevance to real-world landscapes. Thus it is difficult for ecologists working 
at landscape extents to directly elucidate mechanisms that link patterns and processes.

Using a model system for landscapes may be one solution to the problem of replication. Model systems are common in physiology and molecular biology (e.g., Drosophila melanogaster or Escherichia coli) and share traits of "being simpler than other systems of its type, so the property of interest is not obscured by others" (Vitousek 2002, p. 573). Good model systems are generally more useful if they have faster processes and are smaller in size, which enables them to be more amenable to experimental manipulation.

Here, we propose a novel type of landscape - the micro-landscape of tree trunks within a forest standas a model system to understand spatial patterns of rarity. Rather than the traditional perspective of a landscape as a mosaic of patches at kilometers wide extents (Turner 2005), we propose “zooming in" and considering patch-landscape patterns on individual tree trunks within a single stand. Southwood and Kennedy (1983) proposed considering trees as "islands" in an island biogeography context; our proposal expands on this idea. Tree trunks are known to harbour a rich array of microflora and fauna (Prinzing 2001; Wang et al. 2016). In certain environments, such as the one we describe here, and others (e.g., Benítez et al. 2015), tree trunks are covered with a rich diversity of lichens, some of which are common, and some of which are rare (Fig. 1). If we explicitly treat individual lichen thalli as patches within the landscape of the tree trunk, we posit that such trunks will function as model systems. If trees do function as model landscapes, then we expect to see consistent patterns in lichen community gradients along the trunks of trees and on north- versus south-facing sides of the tree, much as patterns of vegetation with elevation are relatively consistent across mountain ranges (Merriam 1890). Thus, when multiple tree trunks are found growing under homogenous stand-level conditions, they will provide replicate experimental "landscape" units for both observational and manipulative experiments. Most importantly, we can assess the species composition of these landscapes in the context of the distribution of rare species, to explicitly test for spatial concordance in rarity, while controlling for broaderscale environmental variation. If species composition is similar across our model landscapes (as per Gaston's criterion 2, above), then there is a higher probability for concordance of rarity for this species; at least at the scale of trees within a stand.

To adequately function as a model system, we need to be confident that replicate units exhibit similar properties, much like the model organisms (e.g., strains of laboratory mice, rats, and bacteria) used in biomedical research (Vitousek 2002). Below we (1) describe our model system in detail, including sampling method and the ecology of our rare species; (2) assess whether our "landscapes" of tree trunks can statistically be considered replicate units; and (3) test whether the landscapes that house a rare species are significantly different in terms of spatial pattern of lichen species composition from those that do not (i.e., whether there is spatial concordance in rarity).

\section{Methods}

Study area

Our study area is a lichen rich forest stand in the Central Avalon Forest Ecoregion, on the island of Newfoundland, Canada $\left(47.32^{\circ} \mathrm{N}, 53.42^{\circ} \mathrm{W}\right.$; Fig. 2). The Central Avalon Forest Ecoregion is composed of ribbed moraine topography, which is a landform that consists of a series of glacially-formed ridges occurring at regular, closely-spaced intervals transverse to the direction of the ice flow. These contain well- to imperfectly-drained Humo-Ferric Podzolic soils, with forests dominated by balsam fir interspersed with bogs (Protected Areas Association 2008). The climate is characterized by cool summers (mean July temperature $16.5^{\circ} \mathrm{C}$ ) and mild winters (mean January temperature $-3.1{ }^{\circ} \mathrm{C}$ ). Average precipitation is $1200 \mathrm{~mm}$ and the region is noted for high levels of fog from the surrounding ocean (Environment Canada Climate Normals, Holyrood Station). The moraine heights range from $\sim 5$ to $15 \mathrm{~m}$ above the surrounding bogs, and this topography, combined with the relative proximity to ocean in four directions creates a phenomenon where coastal fog is often trapped in the forest canopy; the region has been nicknamed "the fog forest".

\section{Boreal felt lichen (Erioderma pedicellatum)}

Our study area is a known "hotspot" for boreal felt lichen (Erioderma pedicellatum; Scheidegger 2003). 


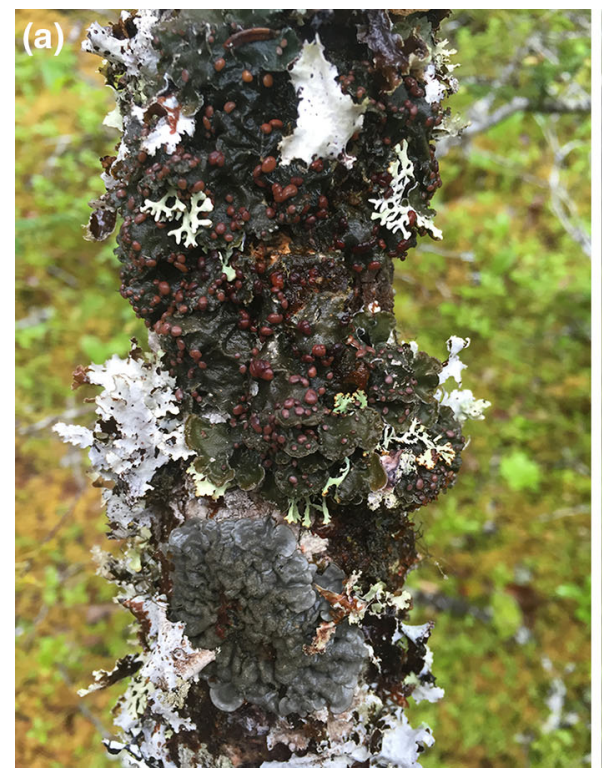

Fig. 1 Photographs of two balsam fir (Abies balsamea) boles in the study area illustrating the rich diversity of lichens found along the trunk. Panel A shows the rare Boreal Felt lichen

Erioderma pedicellatum is an arboreal cyanolichen (its primary photobiont is a cyanobacterium instead of an alga) which historically had an amphi-Atlantic distribution, ranging from Scandinavia to the Atlantic provinces of Canada. It no longer occurs in its historic localities in Sweden (Holien et al. 1995) and the province of New Brunswick. Populations have undergone considerable declines in Norway (Holien 2006) and the province of Nova Scotia (Cameron and Toms 2016). Although E. pedicellatum was discovered in Alaska in 2009 (Stehn et al. 2013), it is estimated that 95-99\% of the global distribution is on the island of Newfoundland, Canada, with approximately a third of the individuals in the study area described above (Goudie et al. 2011; COSWEIC 2014). In Newfoundland, it generally occurs in moist, older stands of pure balsam fir.

\section{Sampling}

Within a single forest stand, we established a sampling transect to sample trees across a gradient of the stand from edge to interior and back to edge. We oriented the transect south to north along the narrow width of a moraine which is approximately $70 \mathrm{~m}$ wide and $170 \mathrm{~m}$ long. The stand is composed of pure balsam fir of varying size (height and diameter), with a ground

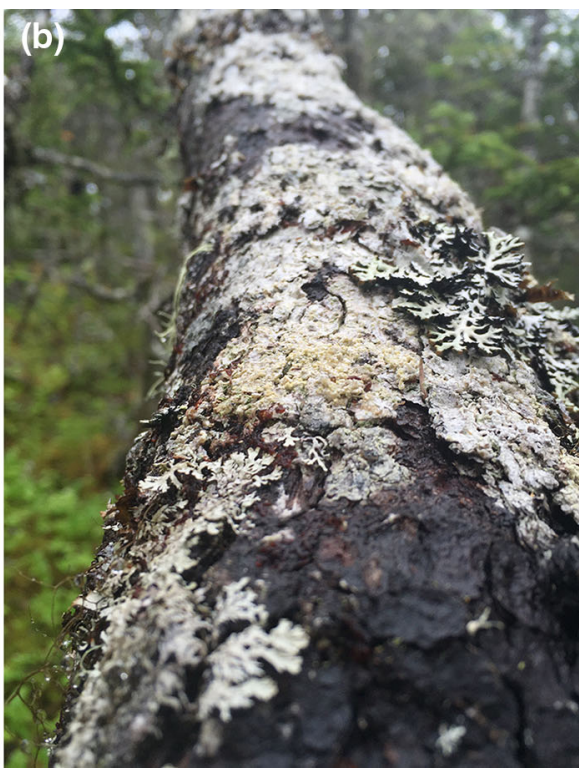

(Erioderma pedicellatum) in the top of the photo (dark green lichen with red dots). Panel B shows a different perspective of a lichen-covered trunk

cover composed mainly ( $>75 \%$ ) of feather moss. We set up sampling stations every $10 \mathrm{~m}$ beginning at the edge of the stand (next to a bog) and ending adjacent to a second bog on the north side of the transect. At each station $(n=8)$ we selected two balsam fir trees, of approximately the same diameter, with each tree located within $2 \mathrm{~m}$ of the centre line of the transect. Between stations, trees were not necessarily similar in size as we wanted to capture a representative sample of the tree sizes (height and diameter) within the stand. For each tree $(n=16)$, we measured height with a Suunto clinometer, diameter at breast height (dbh) using diameter tape, and canopy closure in the four cardinal directions using a spherical densitometer. Four of the trees contained E. pedicellatum. Because we wanted to compare trees with and without the rare species, we selected an additional 8 trees (of similar range of diameters and heights to those on the transect) within $10 \mathrm{~m}$ of the transect which contained E. pedicellatum. This allowed us to compare the "landscape" pattern on 12 trees containing a rare species against 12 without, but all within the same macro-environment.

We measured microclimate directly at each sampling station along the transect using Alpha Mac Tree Archival Tags (hereafter "loggers"). The loggers were deployed $1 \mathrm{~m}$ above the ground, suspended from a tree 
Fig. 2 Location of the study area, Hall's Gullies (indicated by black circle) on the Avalon Peninsula, island of Newfoundland, Canada (approximate location: $47.32^{\circ} \mathrm{N}$,

$\left.53.42^{\circ} \mathrm{W}\right)$. Inset map shows the location of Newfoundland relative to North America

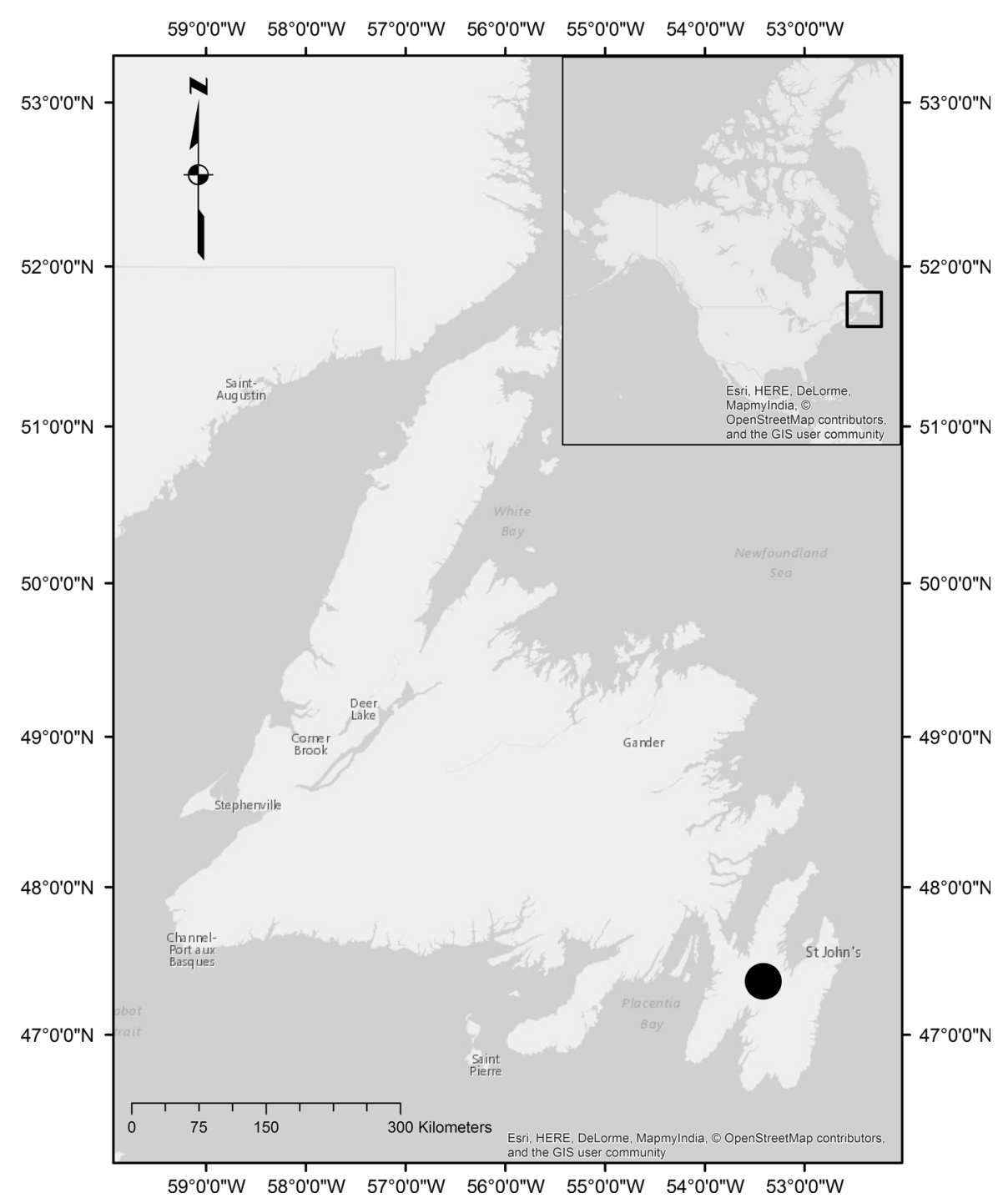

branch using a cable tie. Loggers were programed to record temperature and relative humidity at $6 \mathrm{~h}$ intervals. We recorded data for nearly 2 years, from 1-November-2014 to 22-September-2016.

We sampled lichens in the field between 6-27 October 2015 and 1-8 December 2016 along the north and south facing sides of the trunk of each tree. We used dressmaker's tape to pin a $1 \mathrm{~m}$ "micro-transect" along the trunk, beginning at $0.9 \mathrm{~m}$ from the base (to avoid sampling terricolous lichens). Within $10 \mathrm{~cm}$ "blocks" along the $1 \mathrm{~m}$ micro-transect (10 blocks per micro-transect, 2 micro-transects per tree, 320 blocks total), we identified all macrolichen species using a $10 \times$ hand lens and enumerated the number of individual thalli of each species. Individual thalli were identified by/defined as having an independent continuous body separate from other individuals. We collected a voucher specimen of each species for identification with microscopy and chemical spot tests with Lugol's iodine, para-phenylenediamine in ethyl alcohol, 10 and $20 \%$ potassium hydroxide, and sodium hypochlorite (Brodo et al. 2001). For chemical compounds that could not be detected with spot tests, we used thin layer chromatography following Culberson and Kristinsson (1970) in solvents A and C. We also used chemical spot tests in the field to discriminate species in several genera (i.e., Bryoria, Cladonia, Hypogymnia, and Imshaugia). Voucher specimens 
have been deposited in the Canadian Museum of Nature (CANL).

\section{Statistical analysis}

To confirm that our "landscapes" were as similar as possible from a physical standpoint, we tested for statistical differences in tree height, canopy and dbh between the set of trees with and without the rare lichen using t-tests. We also tested for statistical difference in temperature and relative humidity to confirm that differences in microclimate were not present across the stations.

We summarized lichen species richness and abundance (in terms of counts of individual thalli) within each $10 \mathrm{~cm}$ sample "block". We then tested whether the pattern of lichen "landscapes" in the 12 trees without the rare species were significantly different from each other. If the pattern of species composition along the gradient of the tree trunk and/or between the north and south-facing sides is too dissimilar between individual trees, we would not be able to use trees as a model system for landscapes, since they would not be suitable experimental replicates. We did this in two steps, first by examining tree-level patterns of richness and abundance along the gradient of the distance above ground along the trunk and between north and south sides, and then by using multivariate techniques to examine species-level patterns.

We tested for a significant difference by aspect in lichen richness and abundance between north and south sides of the 12 trees without E. pedicellatum using a Welch's $t$ test. We also used Welch's t-test to compare mean richness in the $10 \mathrm{~cm}$ sample blocks between north and south sides of trees to test if there were different gradients of richness between the sides. We carried out all analyses with R statistical software (version 3.2.4; R Core Team 2016).

We then applied multivariate analyses using the 'vegan' package in R (Oksanen et al. 2016a) to asses overall landscape composition to test our prediction that the pattern of patches (species of lichen thalli) on the landscapes (trees) did not vary between landscapes. We left the data untransformed (to facilitate interpretation), and carried out ordination using nonmetric multidimensional scaling (NMDS) with BrayCurtis dissimilarity (analogous to the Sørensen index in R; Oksanen 2016b), using 2 dimensions and 100 random starts (Minchin 1987). We carried out non- parametric MANOVA (Anderson 2001) with 999 permutations to test for effect of aspect (north vs. south side of tree) while stratifying by tree and then again with a further stratification by location up the trunk of the tree (thereby comparing the lichen community across all sample blocks at a single height up the trunk on the north side versus the south side of the trunk). Similarly, we carried out a non-parametric MANOVA with 999 permutations to test for effect of height up the tree trunk (between 0.9 and $1.9 \mathrm{~m}$ ) while stratifying by tree and by aspect within tree.

To determine if landscapes containing a rare species are different from those where the species is absent, we compared whether the "landscape" pattern of lichen in the $10 \mathrm{~cm}$ sample blocks on the trees which contained E. pedicellatum was similar to those without by performing the same non-parametric MANOVA test described above, but only on the 12 trees that contained the rare lichen. We also compared tree-level patterns of richness and abundance between the trees containing E. pedicellatum and those that did not to see if trees containing the rare lichen differed in their overall richness and abundance. To better visualize the degree of similarity in lichen abundance patterns between all trees (those with and without $E$. pedicellatum), we constructed rank-abundance curves for each tree using the 'BiodiversityR' package (version 2.8-0; Kindt and Coe 2005; Kindt 2017) in R.

\section{Results}

Trees as replicate landscapes

The total number of lichen species found across all trees in the stand was 34 (full list in Online Appendix A.1). For only the trees without the rare lichen, when we disregarded species composition or pattern, there was no significant difference in total lichen richness ( $t=-1.055, p=0.303$ ) or total lichen abundance ( $t=-0.138, p=0.892$ ) between the north and south sides of the trees. Similarly, there was no significant difference in mean richness in the $10 \mathrm{~cm}$ sample blocks between the north and south sides of the trees $(t=-0.138, p=0.982)$.

The non-parametric MANOVA showed that after controlling for between-tree differences, that variation in lichen community pattern (which takes into account species identity and location on the trunk) was 
significantly related to both aspect $(p=0.001$; Table 1) and distance up trunk ( $p=0.001$, Table 2$)$. The NMDS plot by aspect showed variation between north and south sides of the tree (Fig. 3a). There was also a significant pattern by aspect when controlling for location along the trunk within tree $(p=0.004$; Table 3), and location along the trunk when controlling for aspect within tree $(p=0.02$; Table 4$)$.

Are landscapes with rare species different?

Trees sampled did not differ significantly by height $(t=1.2175, \quad p=0.2364), \quad \mathrm{dbh} \quad(t=1.3232$, $p=0.1994)$ or canopy closure $(t=0.20963$, $p=0.8367)$ between the set of 12 trees that contained the rare lichen, and the 12 that did not. When we examined microclimate data, we found no statistically significant difference in temperature $(\mathrm{F}=1.36$, $p=0.2254$, Fig. 4a) across the seven stations (1 logger malfunctioned). There was a statistically significant difference in relative humidity between some stations (Fig. 4b); stations 1-3 and 6 had statistically similar relative humidity as did stations 4,5 and 7 .

The non-parametric MANOVA for trees with $E$. pedicellatum showed very similar results, with a significant pattern in lichen community due to aspect $(p=0.001$; Table 1$)$ and location along the trunk $(p=0.001$; Table 3$)$. These patterns remained significantly related when aspect was stratified by location up the trunk ( $p=0.004$; Table 2$)$ and when location was stratified by aspect ( $p=0.05$; Table 4$)$.

Table 1 Non-parametric MANOVA on Bray-Curtis dissimilarity for lichen community composition along trunks of trees as a function of aspect (north vs. south sides of the trunk) for 12 trees without and 12 trees with a rare lichen (E. pedicellatum)

\begin{tabular}{lccccc}
\hline Source & df & SS & MS & F & $p$ \\
\hline \multicolumn{2}{l}{ Trees without } & E. pedicellatum & & & \\
Aspect & 1 & 0.597 & 0.59702 & 2.94 & 0.001 \\
Residuals & 238 & 48.277 & 0.20284 & & \\
Total & 239 & 48.874 & & & \\
Trees with & E. & pedicellatum & & & \\
Aspect & 1 & 0.766 & 0.76622 & 3.83 & 0.001 \\
Residuals & 238 & 47.613 & 0.20006 & & \\
Total & 239 & 48.380 & & & \\
\hline
\end{tabular}

Table 2 Non-parametric MANOVA on Bray-Curtis dissimilarity for lichen community composition along trunks of trees as a function of location up the trunk (along a $1 \mathrm{~m}$ gradient 0.9-1.9 $\mathrm{m}$ up the trunk) for 12 trees without and 12 trees with a rare lichen (E. pedicellatum)

\begin{tabular}{lrrlll}
\hline Source & df & SS & MS & F & $p$ \\
\hline \multicolumn{7}{l}{ Trees without } & E. & pedicellatum \\
Location & 9 & 2.534 & 0.28154 & 1.3974 & 0.001 \\
Residuals & 230 & 46.340 & 0.20148 & & \\
Total & 239 & 48.874 & & & \\
Trees with & E. & pedicellatum & & & \\
Location & 9 & 2.353 & 0.26141 & 1.3063 & 0.001 \\
Residuals & 230 & 46.027 & 0.20012 & & \\
Total & 239 & 48.380 & & & \\
\hline
\end{tabular}

Given the similar community patterns along the trunk and by aspect between the trees with and without E. pedicellatum, we would expect NMDS plot of lichens on these two groups of trees to overlap considerably. They did, but not perfectly (Fig. 3b). When we looked for differences between the two groups, we found that trees with E. pedicellatum had significantly higher total abundance of lichens $(t=2.713, p=0.01)$ and mean richness within the $10 \mathrm{~cm}$ sample "blocks" $(t=-2.656, p=0.01)$ than trees that did not have the rare lichen. However, there was no significant difference in total tree-level richness $(t=-1.11, p=0.273)$ between trees with and without E. pedicellatum. Across all trees, rank abundance-curves show considerable overlap in the overall pattern of lichen species distribution (Fig. 5).

\section{Discussion}

The pattern of patches of lichens on tree trunks showed considerable consistency across the trees within this single stand. Thus, we propose that this system of arboreal lichens along a tree trunk might be a good model system for replicated landscape analyses. The lichen community pattern along the tree trunks showed significant patterns between trees when stratified by aspect within tree. Lichen patterns were similar across all north-facing sides and all southfacing sides, as well as along the tree trunk. These patterns can been seen as analogous (but on a much smaller scale) to a comparison of elevational gradients 
Fig. 3 Nonmetric multidimensional scaling plots (NMDS) for lichen species (points) on trees (plus signs). a all trees, north (green) versus south (black) side of trunk. b trees which contain the rare lichen Erioderma pedicellatum (black) versus those that do not (green) (a)

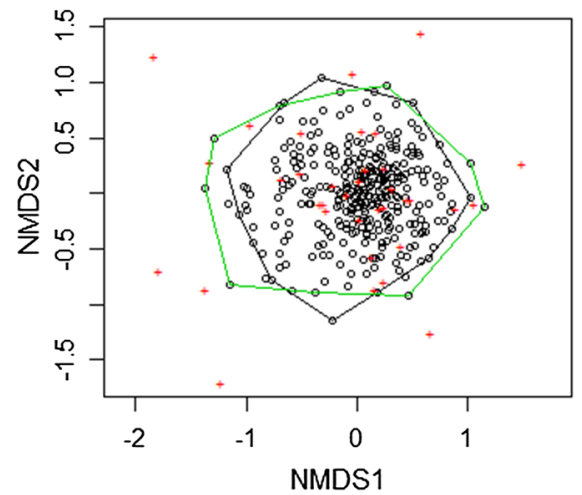

(b)

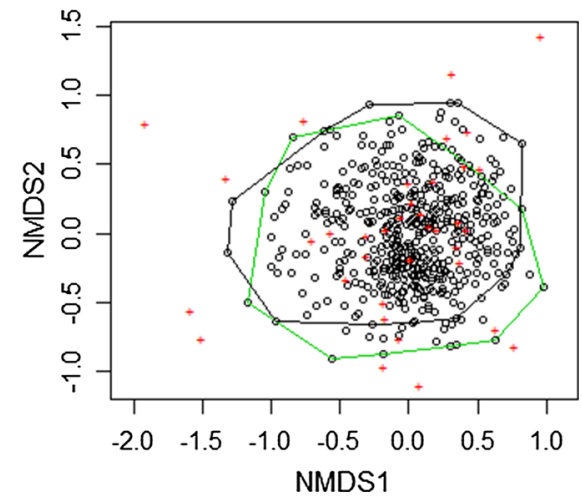

Table 3 Non-parametric MANOVA on Bray-Curtis dissimilarity for lichen community composition along trunks of trees (stratified by location up the trunk) as a function of aspect (north vs. south sides of the trunk) for 12 trees without and 12 trees with a rare lichen (E. pedicellatum)

\begin{tabular}{lcrlll}
\hline Source & df & SS & MS & F & $p$ \\
\hline Trees without & E. pedicellatum & & & \\
Aspect & 1 & 0.597 & 0.59702 & 2.94 & 0.004 \\
Residuals & 238 & 48.277 & 0.20284 & & \\
Total & 229 & 48.874 & & & \\
Trees with & E. & pedicellatum & & & \\
Aspect & 1 & 0.766 & 0.76622 & 3.83 & 0.001 \\
Residuals & 238 & 47.613 & 0.20006 & & \\
Total & 239 & 48.380 & & & \\
\hline
\end{tabular}

Table 4 Non-parametric MANOVA on Bray-Curtis dissimilarity for lichen community composition along trunks of trees (stratified by aspect) as a function of location up the trunk (along a $1 \mathrm{~m}$ gradient $0.9-1.9 \mathrm{~m}$ up the trunk) for 12 trees without and 12 trees with a rare lichen (E. pedicellatum)

\begin{tabular}{lrrlll}
\hline Source & df & SS & MS & F & $p$ \\
\hline \multicolumn{2}{l}{ Trees without } & E. pedicellatum & & & \\
Location & 9 & 2.534 & 0.28154 & 1.3974 & 0.02 \\
Residuals & 230 & 46.340 & 0.20148 & & \\
Total & 239 & 48.874 & & & \\
Trees with & E. & pedicellatum & & & \\
Location & 9 & 2.353 & 0.26141 & 1.3063 & 0.05 \\
Residuals & 230 & 46.027 & 0.20012 & & \\
Total & 239 & 48.380 & & & \\
\hline
\end{tabular}

on north versus south sides of multiple mountain slopes and indicates that the pattern across all sample blocks at each point on the tree (i.e., $0.9 \mathrm{~cm}, 1.0 \mathrm{~m}$, $1.1 \mathrm{~m}$, etc.) were similar across all north and all south sides of trees. Thus we can consider these tree trunks to be good replicate micro-landscapes. Lichen patterns also showed a statistically significant effect of aspect when stratifying by both tree and by location along the trunk within trees, suggesting that the influence of aspect on lichen community patterns is different between trees. Although the patterns are statistically significant, meaning the trees are good replicates, the individual trees are not perfect clones. Despite the slight variation in the rank-abundance between trees, a closer inspection of the rank-abundance data between trees suggested that the same set of species were clustered in both the highest ranks and in the tail (i.e., common species were consistently common across trees, and less-common species were consistently less common). Thus, it appears that the model system of lichen thalli (patches) on trees (landscapes) yields reasonably good replicates (i.e., similar landscape pattern) when we examine the gradient pattern along the trunk and on different aspects of the trunk.

Given this finding, we can conclude that in this system, there is spatial concordance in rarity-rare species are similarly rare across individual tree trunks. There do not appear to be biophysical differences in the trees that contain the rare E. pedicellatum, thus tree size does not explain presence or absence of $E$. pedicellatum between trees in this stand. Trees with $E$. pedicellatum had higher overall abundance-this might suggest there is some attribute of the tree or the location of the tree in the stand which we did not examine which might make it suitable for lichen growth. However, when we compared total lichen 
(a)

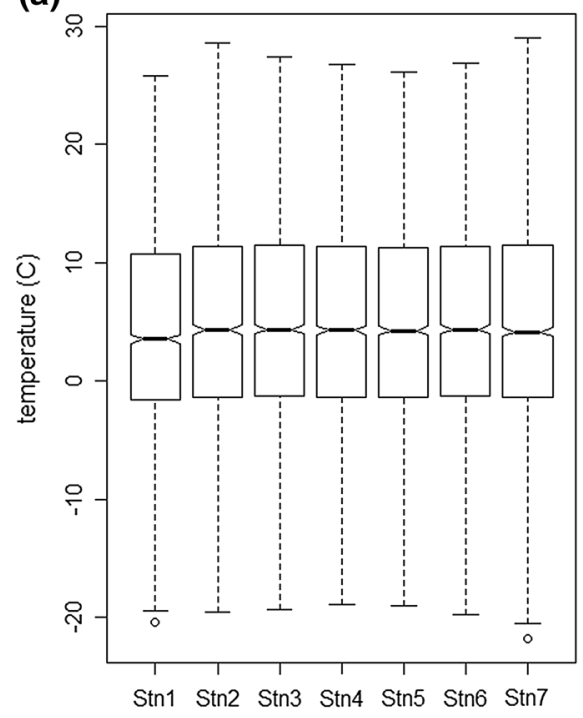

(b)

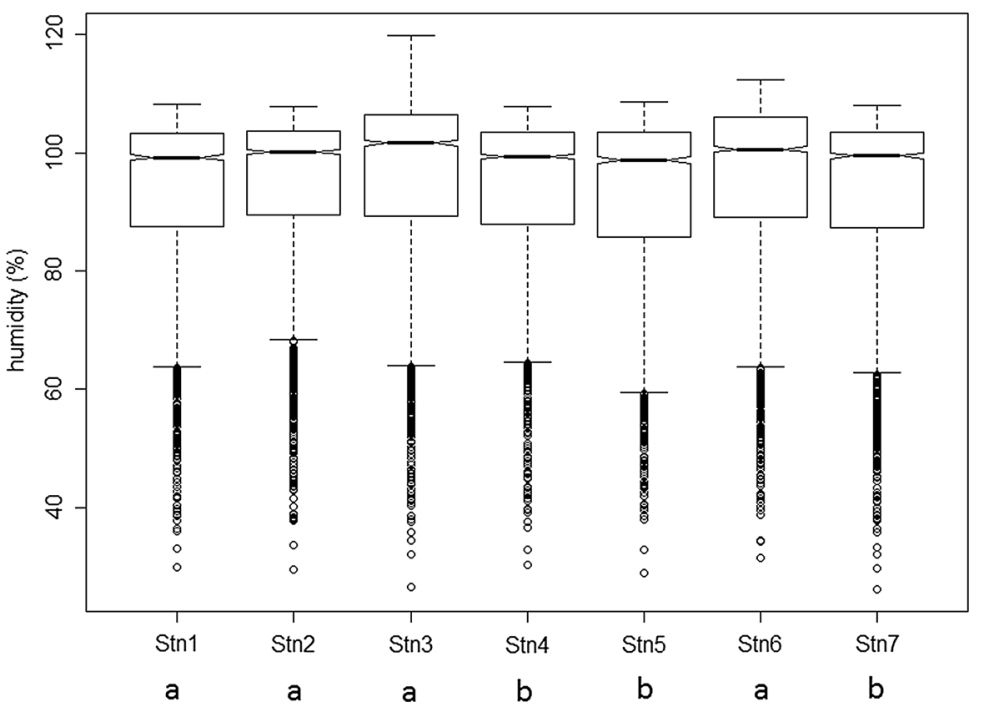

Fig. 4 a. Box plot showing temperature $\left({ }^{\circ} \mathrm{C}\right)$ measured at seven stations along a transect $(\sim 10 \mathrm{~m}$ apart $)$. b. Box plot showing relative humidity $(\%)$ measured at seven stations along a transect ( $\sim 10 \mathrm{~m}$ apart). Temperature and relative humidity were recorded at $6 \mathrm{~h}$ intervals from 01-November-2011 to 22-October-2015 using Alpha Mac Tree Archival Tags placed
$1 \mathrm{~m}$ above the ground, suspended from a tree branch. Dark horizontal line indicates the mean, boxes are the interquartile range and whiskers are the $95 \%$ confidence interval. Data from stations which were statistically similar at $p=0.05$ are indicated by letters below the $\mathrm{x}$-axis labels in Panel b; there were no significant differences in temperature across the stations

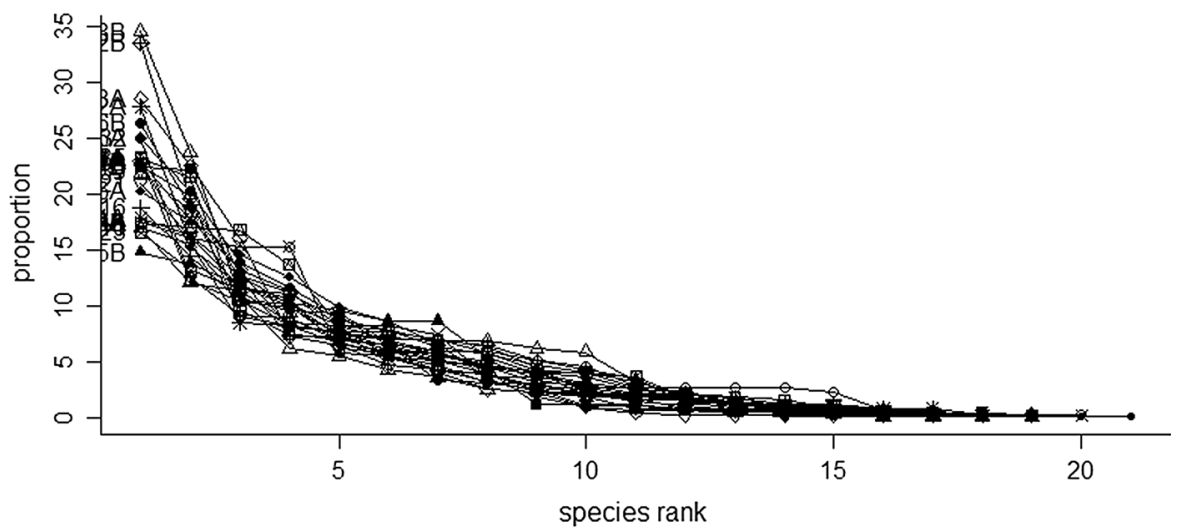

Fig. 5 Rank-abundance curves for lichen diversity on individual trees. Each line and set of symbols represents data from in individual tree. Species are ranked along the $\mathrm{x}$-axis from most to

abundance to relative humidity (which did have some statistically significant differences at different locations), we found no significant correlations ( $r=0.14$, $p=0.7605$ ), thus we do not believe that differences in relative humidity (at least at this spatial scale) affects whether or not $E$. pedicellatum occurs on a given tree. In contrast to our findings, studies from the Alaska population (where the host tree is different) suggest least abundant on each tree in terms of numbers of individuals. The $y$-axis shows the relative abundance of each species compared to the total abundance of lichens on each tree

that tree diameter, crown length, basal area, canopy and distance to water may be important for predicting E. pedicellatum occurrence on individual trees (Stehn et al. 2013). Across its distribution, relationships between photobiont biodiversity and inter-specific interactions are also posited to have an influence (Cornejo et al. 2016) but these patterns are not yet well-understood. Our findings here are based on a 
small sample size (12) of trees with E. pedicellatum; more extensive work on factors influencing $E$. pedicellatum occurrence at tree- and stand-scales in Newfoundland is needed. Our work suggests that statistical modelling to predict E. pedicellatum occurrence can avail of robust within-stand replication, which should facilitate spatially hierarchical models. As with most species, lichen occurrence is likely driven by hierarchically scaled patterns and processes (Lie et al. 2009; Westerberg et al. 2017); our system is amenable to studying questions across hierarchies of within- and between-tree as well as within- and between stands.

Although there were some statistical differences in relative humidity between stations, we doubt whether this difference is biologically significant from the perspective of the lichen physiology. The within group variance was higher than the between group variance (Fligner-Killen median $\chi^{2}=136.44, p<0.001$ ) and lichens have persisted year-round and across multiple years on the trees within this range of relative humidity values. The difference in mean relative humidity between the stations over the 23 months (2767 data points) ranged from 92.92 ( $\pm 14.33 \mathrm{SD}$ ) to 96.88 $( \pm 16.61 \mathrm{SD}) \%$. This range is far smaller than the ranges of relative humidity at which lichens have been observed to be able to continue photosynthetic and other metabolic processes in (Cowan et al. 1979; Bölter et al. 1989). Some lichens can begin gas exchange at $15-20 \%$ water content. Other green alga species may require slightly more, and cyanolichens (which includes $E$. pedicellatum) require closer to 95\% relative humidity most of the time (Büdel and Lange 1991). All of our stations had mean relative humidity well within these biological optima; nearly two-thirds of the data points were above $95 \%$ relative humidity.

Our study suggests that adopting a model system can yield adequate replication for landscape ecology research questions, such as spatial concordance of rarity, or whether landscapes containing rare species are different from those that do not. It could also be used to investigate links between pattern and process across scales (Urban et al. 1987; Urban 2005). For example, in this system, lichen occurrence at broad spatial extents could be influenced by processes such as wind and forest disturbance. At smaller, tree-level extents, the pattern of lichens might influence composition of insect and gastropod herbivores dwelling on the tree (Cameron 2009). Landscape ecologists have struggled with replicability in natural experiments, and can be confounded by issues of pseudoreplication and spatial autocorrelation (Hurlbert 1984; Hargrove and Pickering 1992; Oksanen 2001; Cottenie and DeMeester 2003). Here we had a sample size of 24 trees. We are unaware of any study in landscape ecology with such a high level of replication, with the exception of studies using artificial landscapes. The abundance of trees in many environments suggests that in future studies replication could be increased even more. This may be advantageous for certain questions, but researchers wishing to increase replication of trees-as-landscapes should be cautious if sampled trees are spaced so far apart that they are growing under different environmental conditions. Environmental conditions across replicate units should be controlled as much as possible.

Recently, Bowker et al. (2014) proposed a microscale system somewhat similar to ours, that of soil biocrusts (composed of communities of bryophytes and lichens), as model systems for ecology. Our system differs from Bowker et al. (2014) in that tree trunks may be more clearly delineated from each other than soil crusts (Southwood and Kennedy 1983), which can be more continuous, thus introducing issues of spatial autocorrelation (Hargrove and Pickering 1992). We propose that our system, like the biocrusts model system (Bowker et al. 2014) might be useful to yield insights into landscape-scale questions. For example, here we have addressed the question of whether there is anything that characterizes how rare species are distributed between landscapes. Our case study example for E. pedicellatum found no significant difference between landscapes containing the rare species and those that did not. Bowker et al. (2014) showed that their biocrusts model system could be used to answer questions about patch-size distribution and relationships between landscape patterns and biophysical drivers. We propose that questions such as those proposed by Bowker et al. (2014) might also be addressed using arboreal lichens on tree trunks. Systems such as patches of lichens on trees, or biocrusts (but not ones containing rare species) are also amenable to manipulation, which would allow for more rigorous investigation of questions germane to landscape ecology, such as the response of patches/landscape to disturbance, or the effect of patch patterns on nutrient flows and species 
distributions. For example, Bokhorst et al. (2015) examined links between lichen traits (specifically nutrients and secondary compounds) and invertebrate communities, but they did not consider spatial pattern (which is a dimension of understanding species distributions that landscape ecologists can contribute), nor did they consider replicate studies on different "landscapes". Arboreal lichens occur in many environments, including unique communities in tropical, temperate, and boreal forest biomes, thus this proposed model system might be widely applicable if arboreal lichens in other environments exhibit similar patterns.

Experimentation in landscape ecology is possible, but challenging. Jenerette and Shen (2012) outlined four broad groups of landscape experiment types and identified examples of different methods for experimentation. Jenerette and Shen (2012) do not discuss model systems per se, but our proposed system has characteristics that would make it amenable to at least 8 of the 15 types of experiments they outline. For example, the model system of patches of lichens on trunks of trees could be used to address questions about process variation within and between landscapes, sensitivity to landscape structure and identification of pattern formation factors. For example, by physically removing thalli from a trunk, multiple fragmentation treatments could be implemented and monitored within a small geographic area to address how landscapes respond, and how processes such as nutrients or microfauna are affected. Fragmentation experiments have been carried out in landscape ecology, but usually through natural experiments (e.g., creation of habitat islands through flooding caused by dam building; Wu et al. 2003) or through manipulation of artificial habitats (Haddad et al. 2015). Wilson et al. (2016) outline fundamental questions that still remain about fragmentation, and suggest that to fully understand the process and effects of fragmentation across spatial, temporal and organizational scales, that new techniques are needed. We propose that the model system presented here could be one such technique.

Applying model systems to landscape ecology research might afford ecologists the ability to more rigorously answer questions that have originally been formulated in the context of kilometres-extent landscapes. We have shown that the patterns of lichen thalli "patches" are statistically similar on tree trunk "landscapes" with similar environments and microclimates. Thus we think these lichen-covered tree trunks can be one type of model system which is analogous to patches of different land cover types in a kilometres-extent landscape. While model systems will never be perfect analogues to large-scale systems (Cottenie and DeMeester 2003), the addition of a robust model system to the landscape ecologist's arsenal of simulation experiments, lab-based microcosms, and observations of real-world kilometersextent landscape will enhance the ability to make stronger inferences of how spatial patterns influence ecological processes.

Acknowledgements This research was funded by an NSERC Discovery Grant to YFW. Field work was carried out under Permit No. 2015/16-14 issued by the Department of Environment and Conservation, Government of Newfoundland and Labrador. Thanks to staff at Salmonier Nature Park for providing housing to RTM during fieldwork. YFW thanks M. Pitcher and C. Hanel for introduction and background information on the study site. Thanks are due to T. Sato, M. Fahmy, E. Kissler, T. Padgett, G. Wachinger and M. Wilkes for assistance with field work, to E. Lopez and M. Fahmy for data entry, and to T. Heckford, R. Wigle, D. Jenerette and two anonymous reviewers for constructive feedback on an earlier draft of the manuscript.

Open Access This article is distributed under the terms of the Creative Commons Attribution 4.0 International License (http:// creativecommons.org/licenses/by/4.0/), which permits unrestricted use, distribution, and reproduction in any medium, provided you give appropriate credit to the original author(s) and the source, provide a link to the Creative Commons license, and indicate if changes were made.

\section{References}

Alahuhta J, Johnson LB, Olker J, Heino J (2014) Species sorting determine variation in the community composition of common and rare macrophytes at various spatial extents. Ecol Complex 20:61-68

Anderson MJ (2001) A new method for non-parametric multivariate analysis of variance. Austral Ecol 26:32-46

Benítez A, Prieto M, Aragón G (2015) Large trees and dense canopies: key factors for maintaining high epiphytic diversity on trunk bases (bryophytes and lichens) in tropical montane forests. Forestry 88:521-527

Bokhorst S, Asplund J, Kardol P, Wardle D (2015) Lichen physiological traits and growth forms affect communities of associated invertebrates. Ecology 96:2394-2407

Bölter M, Kappen L, Meyer M (1989) The influence of microclimatic conditions on potential photosynthesis of Usnea sphacelata: a model. Ecol Res 4:297-307 
Bowker MA, Maestre FT, Eldridge D, Belnap J, CastilloMonroy A, Escolar C, Soliveres S (2014) Biological soil crusts (biocrusts) as a model system in community, landscape and ecosystem ecology. Biodivers Conserv 23:1619-1637

Brodo IM, Sharnoff SD, Sharnoff S (2001) Lichens of North America. Yale University Press, New Haven

Büdel B, Lange OL (1991) Water status of green and blue-green phycobionts in lichen thalli after hydration by water vapor uptake: do they become turgid? Plant Biology 104:361-366

Cameron R (2009) Are non-native gastropods a threat to endangered lichens? Can Field Nat 123:169-171

Cameron RP, Neily T (2008) Heuristic model for identifying the habitats of Erioderma pedicellatum and other rare cyanolichens in Nova Scotia, Canada. Bryologist 111:650-658

Cameron RP, Neily T, Clapp H (2013) Forest harvesting impacts on mortality of an endangered lichen at the landscape and stand scales. Can J For Res 43:507-511

Cameron RP, Toms B (2016) Population decline of endangered lichen Erioderma pedicellatum in Nova Scotia, Canada. Botany 94:1-7

Cornejo C, Scheidegger C (2016) Cyanobacterial gardens: the liverwort Frullania asagrayana acts as a reservoir of lichen photobionts. Environ Microbiol Reports 8:352-357

Cornejo C, Nelson PR, Stepanchikova I, Himelbrant D, Jørgensen P-M, Scheidegger C (2016) Contrasting pattern of photobiont diversity in the Atlantic and Pacific populations of Erioderma pedicellatum (Pannariaceae). The Lichenologist 48:275-291

COSEWIC (Committee on the Status of Endangered Wildlife in Canada) (2014) COSEWIC assessment and status report on the Boreal Felt Lichen Erioderma pedicellatum, Boreal population and Atlantic population, in Canada. Committee on the Status of Endangered Wildlife in Canada, Ottawa

Cottenie K, DeMeester L (2003) Comment to Oksanen (2001): reconciling Oksanen (2001) and Hurlbert (1984). Oikos 100:394-396

Cowan DA, Green TGA, Wilson AT (1979) Lichen metabolism. 1. The use of tritium labeled water in studies of anhydrobiotic metabolism in Ramalina celastri and Peltigera polydactyla. New Phytol 82:489-503

Culberson CF, Kristinsson H (1970) A standardized method for the identification of lichen products. J Chromatogr 46:85-93

Gaston KJ (1994) Rarity. Population and community biology series 13. Chapman and Hall, London

Goudie I, Scheidegger C, Hanel C, Munier A, Conway E (2011) New population model help explain declines in the globally rare boreal felt lichen Erioderma pedicellatum in Newfoundland. Endanger Species Res 13:181-189

Haddad NM, Brudvig LA, Clobert J, Davies KF, Gonzalez A, Holt RD, Lovejoy TE, Sexton JO, Austin MP, Collins CD, Cook WM, Damschen EI, Ewers RM, Foster BL, Jenkins CN, King AJ, Laurance WF, Levey DJ, Margules CR, Melbourne BA, Nicholls AO, Orrock JL, Song DX, Townsend JF (2015) Habitat fragmentation and its lasting impact on Earth's ecosystems. Sci Adv 1:e1500052

Hargrove WW, Pickering J (1992) Pseudoreplication: a sine qua non for regional ecology. Landscape Ecol 6:251-258
Holien H (2006) Trøderlav Erioderma pedicellatum. Artsdatabankens Faktaark nr. 3

Holien H, Gaarder G, Hapnes A (1995) Erioderma pedicellatum still present, but highly endangered in Europe. Graphis Scripta 7:79-84

Hurlbert SH (1984) Pseudoreplication and the design of ecological field experiments. Ecol Mongr 54:187-211

Ims RA (2005) The role of experiments in landscape ecology. In: Wiens JA, Moss MR (eds) Issues and perspectives in landscape ecology. Cambridge University Press, Cambridge, pp 70-78

Jenerette GD, Shen W (2012) Experimental landscape ecology. Landscape Ecol 27:1237-1248

Kindt R (2017) BiodiversityR package, version 2.8-0. Package for community ecology and sustainability analysis. CRAN repository

Kindt R, Coe R (2005) Tree diversity analysis. A manual and software for common statistical methods for ecological and biodiversity studies. World Agroforestry Centre (ICRAF), Nairobi. ISBN 92-9059-179-X

Kunin WE, Gaston KJ (1997) The biology of rarity. Causes and consequences of rare-common differences. Population and community biology series 17 . Chapman and Hall, London

Lie MH, Arup U, Grytnes J-A, Ohlson M (2009) The importance of host tree age, size and growth rate as determinants of epiphytic lichen diversity in boreal spruce forests. Biodiver Conserv 18:3579-3596

Maass WSG, Yetman DJ (2002) COSWEIC assessment and status report on the boreal felt lichen Erioderma pedicellatum. COSEWIC Canadian Wildlife Service, Ottawa

McGeoch MA, Chown SL (1997) The spatial variability of rare and common species in a gall-inhabiting Lepidoptera community. Ecography 20:123-131

Merriam CH (1890) Excerpts from "Results of a biological survey of the San Francisco mountain region and the desert of the Little Colorado, Arizona. North American Fauna no. 3 U.S. Department of Agriculture, Washington, DC. As published. In: Lomolino MV, Sax DF, Brown JH (eds) Foundations of biogeography, classic papers with commentaries. The University of Chicago Press, Chicago, pp 202-233

Minchin PR (1987) An evaluation of relative robustness of techniques for ecological ordinations. Vegetatio 69:89-107

Murray BR, Thrall PH, Gill AM, Nicotra AB (2002) How plant life-history and ecological traits relate to species rarity and commonness at varying spatial scales. Austral Ecol 27:291-390

Oksanen L (2001) Logic of experiments in ecology: is pseudoreplication a pseudoissue? Oikos 94:27-38

Oksanen J, Blanchet GF, Kindt R, Legendre P, McGlinn D, Minchin PR, O’Hara RB, Simpson GL, Solymos P, Stevens MHH, Szoecs E, Wagner, H (2016a) Vegan: Community Ecology Package. $\mathrm{R}$ package version 2.3-4. CRAN Repository

Oksanen J (2016b) Notes for vegdist. In: Oksanen J, Blanchet GF, Kindt R, Legendre P, McGlinn D, Minchin PR, O'Hara RB, Simpson GL, Solymos P, Stevens MHH, Szoecs E, Wagner H Vegan: Community Ecology Package. R package version 2.3-4. CRAN Repository 
Prinzing AJ (2001) Use of shifting microclimate mosaics by arthopods on exposed tree trunks. Ann Entomol Soc Am 94:210-218

Protected Areas Association of Newfoundland and Labrador (2008) Avalon Forest Ecoregion Brochure. http://www. env.gov.nl.ca/env/publications/parks/ecoregions/island_ 5_avalon_forest.pdf Accessed 20 May 2016)

Rabinowitz D (1981) Seven forms of rarity. In: Synge H (ed) Biological aspects of rare plant conservation. Wilely, Chichester

R Core Team (2016) R: A language and environment for statistical computing. R Foundation for Statistical Computing, Vienna, Austria. URL https://www.R-project.org/

Scheidegger C (2003) Erioderma pedicellatum. The IUCN red list of threatened species 2003: e.T43995A10839336. Available from http://dx.doi.org/10.2305/IUCN.UK.2003. RLTS.T43995A10839336.en

Southwood TRE, Kennedy CEJ (1983) Trees as islands. Oikos 411:359-371

Stehn SE, Nelson PR, Roland CA, Jones JR (2013) Patterns in the occupancy and abundance of the globally rare lichens Erioderma pedicellatum in Delali National Park and Preserve, Alaska. Bryologist 116:1-14

Turner MG (2005) Landscape ecology in North America: past, present, and future. Ecology 86:1967-1974

Urban DL (2005) Modeling ecological processes across scales. Ecology 86:1996-2006
Urban DL, O’Neill RV, Shugart HH (1987) Landcape ecology. Bioscience 37:119-127

Vitousek PM (2002) Oceanic islands as model systems for ecological studies. J Biogeogr 29:573-582

Wang X, Long W, Schamp BS, Yang X, Kang Y, Xie Z, Xiong M (2016) Vascular epiphyte diversity differs with host crown zone and diameter, but not orientation in a tropical cloud forest. PLoS ONE 11:e0158548

Westerberg LM, Muhammadi UH, Bergman K-O, Milberg P (2017) Spatial pattern of occurrence of epiphytic lichens on oaks in a heterogenous landscape. Acta Oecologica 84:64-71

Wiens JA, Milne BT (1989) Scaling of 'landscapes' in landscape ecology, or, landscape ecology from a beetle's perspective. Landscape Ecol 3:87-96

Wiersma YF, Skinner R (2011) Development of a predictive distribution model for Erioderma pedicellatum (Boreal felt lichen) for the island of Newfoundland, Canada. Endanger Species Res 15:115-127

Wilson MC, Chen X-Y, Corlett RT, Didham RK, Ding P, Holt RD, Holyoak M, Hu G, Hughes AC, Jiang L, Laurance WF, Liu J, Pimm SL, Robinson SK, Russo SE, Si X, Wilcove DS, Wu J, Yu M (2016) Habitat fragmentation and biodiversity conservation: key findings and future challenges. Landscape Ecol 31:219-227

Wu J, Huang J, Han X, Xie Z, Gao X (2003) Three-Gorges Dam-experiment in habitat fragmentation? Science 300:1239-1240 